University of Nebraska - Lincoln

DigitalCommons@University of Nebraska - Lincoln

Faculty Publications: Department of Entomology

Entomology, Department of

2008

\title{
Simulations with Elaborated Worked Example Modeling: Beneficial Effects on Schema Acquisition
}

\author{
Debra K. Meier \\ University of Nebraska-Lincoln, dmeier1@unl.edu \\ Karl J. Reinhard \\ University of Nebraska-Lincoln, kreinhard1@mac.com \\ David O. Carter \\ University of Nebraska-Lincoln, dcarter2@unl.edu \\ David W. Brooks \\ University of Nebraska-Lincoln, dbrooksne@gmail.com
}

Follow this and additional works at: https://digitalcommons.unl.edu/entomologyfacpub

Part of the Entomology Commons

Meier, Debra K.; Reinhard, Karl J.; Carter, David O.; and Brooks, David W., "Simulations with Elaborated Worked Example Modeling: Beneficial Effects on Schema Acquisition" (2008). Faculty Publications: Department of Entomology. 193.

https://digitalcommons.unl.edu/entomologyfacpub/193

This Article is brought to you for free and open access by the Entomology, Department of at DigitalCommons@University of Nebraska - Lincoln. It has been accepted for inclusion in Faculty Publications: Department of Entomology by an authorized administrator of DigitalCommons@University of Nebraska - Lincoln. 
Published in Journal of Science Education and Technology 17 (2008), pp. 262-273; doi: 10.1007/s10956-008-9096-4 Copyright (C) 2008 Springer Science+Business Media, LLC. Used by permission.

This article describes the dissertation study completed by Debra K. Meier under the guidance of David W. Brooks at the University of Nebraska-Lincoln.

Published online March 25, 2008

\title{
Simulations with Elaborated Worked Example Modeling: Beneficial Effects on Schema Acquisition
}

\author{
Debra K. Meier, ${ }^{1}$ Karl J. Reinhard, ${ }^{2}$ David O. Carter, ${ }^{3}$ and David W. Brooks ${ }^{4}$ \\ 1) Extended Education and Outreach, University of Nebraska-Lincoln, 900 North 22nd Street, \\ Lincoln, NE 68588-8900, USA \\ 2) School of Natural Resources, University of Nebraska-Lincoln, Lincoln, NE 68588-0987, USA \\ 3) Department of Entomology, University of Nebraska-Lincoln, Lincoln, NE 68588-0816, USA \\ 4) Department of Teaching, Learning, and Teacher Education, University of Nebraska-Lincoln, \\ Lincoln, NE 68588-0355, USA \\ Corresponding author - Debra K. Meier, email dmeier1@unl.edu
}

\begin{abstract}
Worked examples have been effective in enhancing learning outcomes, especially with novice learners. Most of this research has been conducted in laboratory settings. This study examined the impact of embedding elaborated worked example modeling in a computer simulation practice activity on learning achievement among 39 undergraduate students within a classroom environment. The students from one introductory forensic science course were randomly assigned to one of two groups that worked through computer-based simulations containing worked example modeling conditions presented in varied order. The computer software administered the modeled simulations, prior knowledge test, pretest, posttests, and a second domain test. Findings from this study suggest that embedded worked example modeling within practice simulations can be an effective method for transfer of learning with novice learners.
\end{abstract}

Keywords: worked examples, modeling, simulations, research, schema

The ability of students to acquire problem solving skills is often discussed in terms of how to provide novice students with the metacognitive skills of a domain expert. This is not saying that, by doing so, all students will become experts in that domain. Bransford et al. (2000) concluded, "[R]esearchers study experts and the ways they solve problems not in the belief that every student should become an expert, but because the study of expertise shows what successful learning looks like" (as stated in Bruning et al. 2004, p. 346).

So how can the novice, as well as the more advanced student, acquire expert methods of problem solving and develop the domain schema for successful transfer of content concepts and principles? To proceed in finding some possible solutions to this question one must review the differences between how experts approach solving problems with the way in which a novice would approach solving the same problems. Major differences between experts and novices include:

1. Experts organize domain knowledge around the big ideas and core concepts of that domain.

2. Experts use a working-forward (means-ends) strategy approach, while a novice may use a workingbackward strategy.

3. Experts have the ability to recognize meaningful patterns of information. This is done through their ability to chunk information and organize the information into schema.

4. In science domains, research has shown experts using 'qualitative analysis' (Larkin 1977) or 'physical 
intuition' (Simon and Simon 1978). This trait allows the expert to develop elaborate representations of the problem, including a sketch or other types of physical versions of the problem.

5. Experts possess more domain knowledge than novices and are able to more efficiently search their database of information for the problem and the retrieval of the necessary information is acquired in a more fluent manner. This then causes a minimal amount if any cognitive load, allowing for more focus to be placed on more demanding parts of the problem.

6. Experts possess more procedural knowledge than novices (Bruning et al. 2004).

A key difference between the expert and the novice learner is in how they deal with cognitive load that does not contribute to learning. The understanding of the mechanism of cognitive load, the mental effort required to complete a task, is key to development of effective instructional design and its learning outcome. Cognitive load is associated with working memory. Working memory actively processes information and makes meaning out of this information. Working memory, however, is limited in how much information it can hold and process at any time (Baddeley 1986). There are at least two types of cognitive load that working memory needs to deal with when processing information, intrinsic and extraneous. The intrinsic load is determined by the degree of interactivity between elements of the actual learning task, in other words, by the inherent properties of the to-be-learned material. Complex tasks present a high degree of interactivity, especially for novice learners and, thus, a high intrinsic cognitive load.

Extraneous cognitive load can be introduced through the design of the instructional materials. Thus, this source of cognitive load is potentially controllable. Poorly designed instructional materials and/or layout of content can greatly increase the amount of extraneous cognitive load associated with a learning task; whereas well-designed materials can greatly reduce it.

The acquisition of schema, a mental framework that organizes the domain knowledge needed to develop expertise, is an important part of effective learning and problem solving. "...since learning consists largely of schema acquisition, an element that needs to be learned is a schema that needs to be acquired" (Sweller 1999, p. 28). An expert's schema has incorporated numerous elements within a complex learning task into fewer but larger elements (chunks) allowing the working memory to hold more of the information at one time. The novice learner, on the other hand, has not formed the schema for a given complex task and thus must process each of the multiple elements individually. This may exceed the capacity of the working memory requiring it to hold too many elements at one time and causing it to fail before the task is accomplished. This is referred to as cognitive overload.

Cognitive load is always present in learning activities. Poorly designed factors within the instructional design, unrelated to the learning content, often can be the source that imposes extraneous cognitive load on the learner and can hinder schema acquisition. This is particularly detrimental in learning complex tasks with high intrinsic cognitive load. However, when the educational content of the learning task has a high intrinsic cognitive load, the use of appropriate instructional design strategies can minimize the amount of extraneous cognitive load placed upon the learners and help enhance the acquisition of schema for these complex tasks.

Research in many well-structured domains in science (e.g., physics, mathematics, computer science) has provided instructional design strategies that incorporate this look at expert learning. Worked examples is one strategy used in problem solving environments that utilizes expert problem solutions for the novice learners to apprentice by. The worked example design typically includes: statement of problem, worked solution for the problem represented in steps an expert would follow, and the solution to the problem.

Utilization of learning by example is not a new idea. Research in learning by example has been a major educational theme for the past four decades. Atkinson et al. (2000) report the interest in learning-by-example paradigm for examination and description of concept formation processes was strong in the mid-1950s through the 1970s (Bourne et al. 1964; Bruner et al. 1956; Tennyson et al. 1972). Recent worked example research, however, varies from the earlier learning-by-example research. More recent research focuses on how students learn schema and how experts vs. novices approach problem solving. This is in contrast to the earlier learningby-example research that focused on presentation and sequencing of examples while facilitating concept learning. Most of the recent research has been conducted in laboratory settings. Some studies, however, have been conducted during classroom instruction where the primary focus has been in well-structured content domains (Carroll 1994; Ward and Sweller 1990; Zhu and Simon 1987).

The Atkinson et al. (2000, p. 186) worked example review proposes instructional principles derived from the worked example research that moderate their effectiveness. The three principles are:

1. "Intra-example features, in other words, how the example is designed, particularly the way the example's solution is presented.

2. Inter-example features, principally certain relationships among multiple examples and practice problems within a lesson. 
3. Individual differences in example processing on the part of students, especially the way in which students 'self explain' the examples".

Research relating to issues of the first principle includes Mayer and Moreno's (2003) nine ways of reducing cognitive load in multimedia learning. Also Jeung et al.'s (1997) research study in geometry utilized worked examples incorporating the temporal contiguity effect (an audio-visual condition) that included the signaling effect in the form of visual cues directing the learner's attention to the part of the diagram being discussed in the narration. "According to Jeung et al. (1997), simply adding electronic flashing to a dual-mode example can lead to enhanced learning, even under high-search conditions, by encouraging the learner to devote cognitive resources to understanding the example, as opposed to dedicating them to search and recognition" (Atkinson et al. 2000, p. 189). Chandler and Chaillé (1993) have hypothesized that within computer simulations "... process highlighters promote awareness of the underlying principles and mechanisms at work in a given situation" (p. 242). Their research tentatively verified this hypothesis, but they stress that future research needs to "...help clarify issues concerning transfer of knowledge and the effectiveness of different types of process highlighters, as well as applicability to a broader range of problems" (p. 261). Catrambone (1994a, 1994b, 1995, 1996), has reported in Atkinson et al. (2000), has also determined that two techniques (labels and visual separation of steps) designed to accentuate the sub-goals of an example, were most efficient in performance enhancement.

Research that has focused on inter-example features of the lesson design, propose four issues for discussion:

1. How many examples should be presented during the instruction?

2. Should the examples vary and, if so, how should they vary within the lesson?

3. How can the "surface stories" be varied to enhance the instruction?

4. How should the worked examples be mixed in with the practice?

Though most worked example researchers propose that it is necessary for multiple examples to be presented when students are learning complex concepts (e.g., Cooper and Sweller 1987; Gick and Holyoak 1983; Reed 1993; Spiro et al. 1989; Sweller and Cooper 1985), a direct study of the question; "Can one example facilitate learning?" was done by Reed and Bolstad (1991). Their prediction, however, was that there is a need for at least two (one simple and one complex) examples to effectively facilitate learning of complex concepts. According to their conclusions, their prediction of one sim- ple and one complex example being sufficient to accomplish both near and far transfer was shown to hold true. However, Ahn et al. (1992, p. 391) concluded from their research results using an explanation-based learning approach on concept formation, that " $[\mathrm{H}]$ uman learners can acquire a schema from a single example in knowledge-rich domains, but not in knowledge-poor domains". Renkl (1997) found that multiple examples were not necessary when near transfer was the goal of the learned knowledge. However, it seems to be of importance for far transfer. Renkl et al. (1998) state that results from their previous studies (Stark et al. 1995) found multiple examples without supported learning equates to poor performance. One must bear in mind that when presenting worked examples as part of instruction, "[T]he number of examples that can be used for teaching a particular idea may be constrained in practice by such issues as instructional time and problem complexity, since teachers often cannot present many complex examples" (Atkinson et al. 2000, p. 202).

If one chooses to present multiple examples, research by Paas and van Merriënboer (1994) suggests that variability of the examples produce transfer benefits, but situations where practice is not supported by cognitive load reduction, such as instruction utilizing worked examples, variability does not provide a significant benefit. Quilici and Mayer (1996) conducted several studies that examined structure-emphasis compared to surface-emphasis in worked examples. The structure emphasizing techniques were found to be more effective in enhancing learning and they demonstrate that only looking at surface features of a problem is not effective. This ties into a key difference in how an expert works through problem solving compared to novices, in that the expert analyzes the deep structure of a problem where a novice can become caught up in only focusing on the surface structure. This research has also shown that utilization of only a fixed number of cover stories across various problem types is preferable in novice learning. In addition to this finding, additional studies report that variability of worked examples is not to be recommended due to producing an overloading condition for the users (Renkl et al. 1998).

Mixing worked examples in with practice raises the question as to whether or not worked examples pairing with practice problems is the most effective sequencing. Based upon findings by Trafton and Reiser (1993, p. 1022), the assertion is made that "[T]he most efficient way to present material to acquire a skill is to present an example, then a similar problem to solve immediately following". These pairing of worked examples and practice problems should also be interspersed throughout the instruction as opposed to presenting a block of worked examples and then a block of practice problems. 
Modeling, too, is described as a way of demonstrating the components that make up an expert's method of complex procedural problem solving. Meichenbaum's (1977) proposed cognitive modeling includes six steps for effective instruction. The combination of worked examples and modeling, that includes a specific scenario worked out in steps through a modeled format, then becomes a hybrid learning support strategy that research is suggesting needs further study in classroom environments.

\section{Method}

The context of an authentic forensic case was used in this study. Students were assigned the role of a forensic palynologist, using pollen to determine diet and/or establish linkages between people, places and/or objects on a crime scene investigation. Using the interactive computer simulations developed for this study, each student gathered pollen data. The students incorporated these data with other crime scene evidence to support a working hypothesis on "where the victim was killed" and "where the body mummified." Four pollen simulations representing the real samples that were collected from this crime scene were the student "samples." The students' input into the simulations provided the data collected for this study.

\section{Population and Sample}

The population of this sample included 39 undergraduate students enrolled in an introductory forensic science course. The students used this course as an elective in their program of study due to the fact that it was not officially part of an undergraduate program. Demographic information included: an age range of 19-47; 25 seniors, 11 juniors, and 3 sophomores; and 20 male, 19 female. The students' majors represented 10 science and 29 non-science categories.

\section{Procedure}

The instruction included 6 days: one day in a computer laboratory, three lectures, and then a second and third day in a computer laboratory. A random project identification number was assigned to each student. The students registered for use of the computer site at the beginning of the first day in a computer laboratory. They then worked through a simulation that only had written label cues for progressing through the site (the prior knowledge test). Every student did the same simulation.

The lectures on pollen analysis in forensic science included distribution of handouts consisting of two sheets of pollen identification pictures and information to use in place of a pollen key in the simulations. The students were instructed to review the pollen types before attending the second and third computer class. An additional pollen ID sheet was distributed to all of the students at the beginning of the second computer class period with the statement that forensic palynologists continue to learn new pollen types. The second and third computer class sessions directly followed the lectures on pollen.

As the students arrived at the computer lab for the second computer class session, the instructor randomly assigned them either to group ID AB (treatment Asimulation with embedded modeled worked example with elaboration, was given first, followed by treatment $\mathrm{B}$ - simulation with embedded modeled worked example without elaboration) or group ID BA (treatment B was given first, followed by treatment A). The session then began with all of the students working through a simulation similar to the prior knowledge simulation. This was the pretest simulation. The data from the pretest simulation were analyzed for instrument reliability. Following the pretest, the students worked through the treatment condition that corresponded to the first letter in their group ID. Group AB worked through treatment A while Group BA worked through treatment B. A different pollen assemblage slide simulation was used with each treatment. The same simulation test (posttest \#1) followed both of the treatments. This posttest \#1 simulation was the same as the pretest simulation.

At the beginning of the final computer class session, the students worked through the treatment condition that corresponded to the second letter in their group ID. Again, the posttest simulation (posttest \#2) followed the treatment simulations. Posttest \#2 was also the same simulation as the pretest and posttest \#1. Following the posttest \#2 simulation, the students all worked on a simulation representing pollen from an archaeological site. Learning support was not embedded in this simulation. The students received feedback on their performance with the computer simulations by the end of the twelfth week of class.

\section{Variables and Measures}

The first non-treatment practice simulation following the topic lectures served as the pretest. The two treatment conditions are: 1 . Treatment $\mathrm{A}-$ Worked example modeling with elaboration. 2. Treatment $\mathrm{B}-$ Worked example modeling without elaboration. The treatments were represented in movie formats that were embedded within a practice simulation. The worked example modeling movies, both non-elaborated and elaborated, represented the expert analysis of the pollen sample found in the prior knowledge test simulation. Each treatment was embedded in a different practice simulation. Table 1 provides an example comparison between the elaborated and non-elaborated narration. 
Table 1. Elaborated narration and non-elaborated narration examples

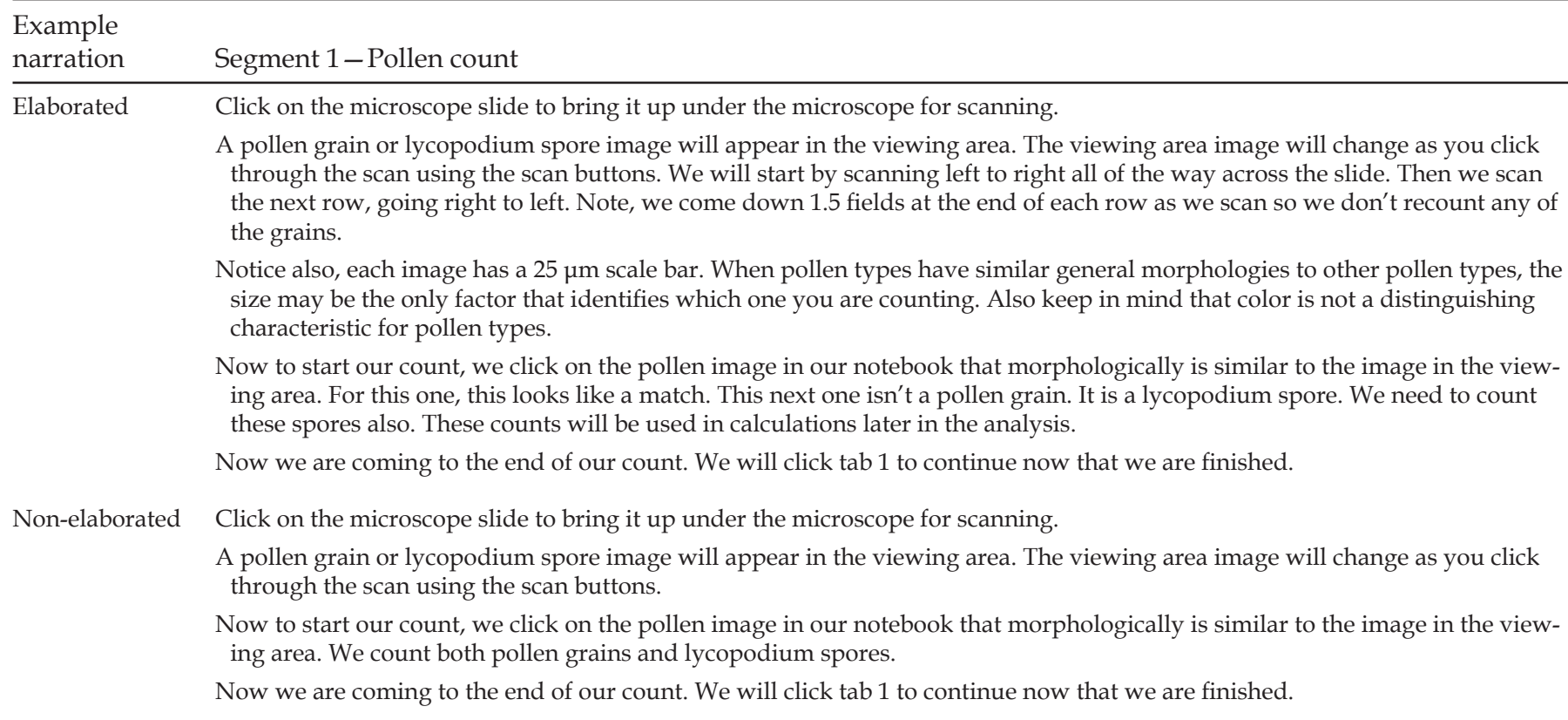

A computer practice simulation that contains no embedded treatment followed all treatment simulations. This simulation was the same as the pretest simulation. This follow-up computer simulation was used as the posttest. The final simulation without embedded support had a similar structure but was in a different domain (archaeology) (Figure 1).

A possible 155 point score was assessed for each of the prior knowledge, pretest, and posttests practice simulations. The archaeology practice simulation had a possible 65 point score. The archaeology simulation's first three segments were scored the same as the prior knowledge, pretest and posttests, but the interpretation (final segment) score was limited to one multiple-choice question. This question was "Which scenario does this pollen assemblage represent?" This is the same overall interpretation question asked in the other three tests.

\section{Content Validity and Reliability}

The simulation instrument's validity was established by three expert forensic palynologists. All parts of the instrument were reviewed for authentic representation of the microscopic pollen analysis process. Cronbach's alpha scores were used to determine reliability of the instrument with this data set.

\section{Treatments}

All students were required to utilize both treatment simulations. Treatment A utilized one 3 min $38 \mathrm{~s}$ narrated full process example presentation and four narrated component presentations, varying in duration ( 1 min $5 \mathrm{~s} ; 17 \mathrm{~s} ; 39 \mathrm{~s}$; and $1 \mathrm{~min} 1 \mathrm{~s}$ ). Treatment B utilized one $1 \mathrm{~min} 55 \mathrm{~s}$ narrated full process example presentation and four narrated component presentations, ranging in duration (20 s; $8 \mathrm{~s} ; 27 \mathrm{~s}$; and $37 \mathrm{~s}$ ). All presentations provided a modeled worked example of the same

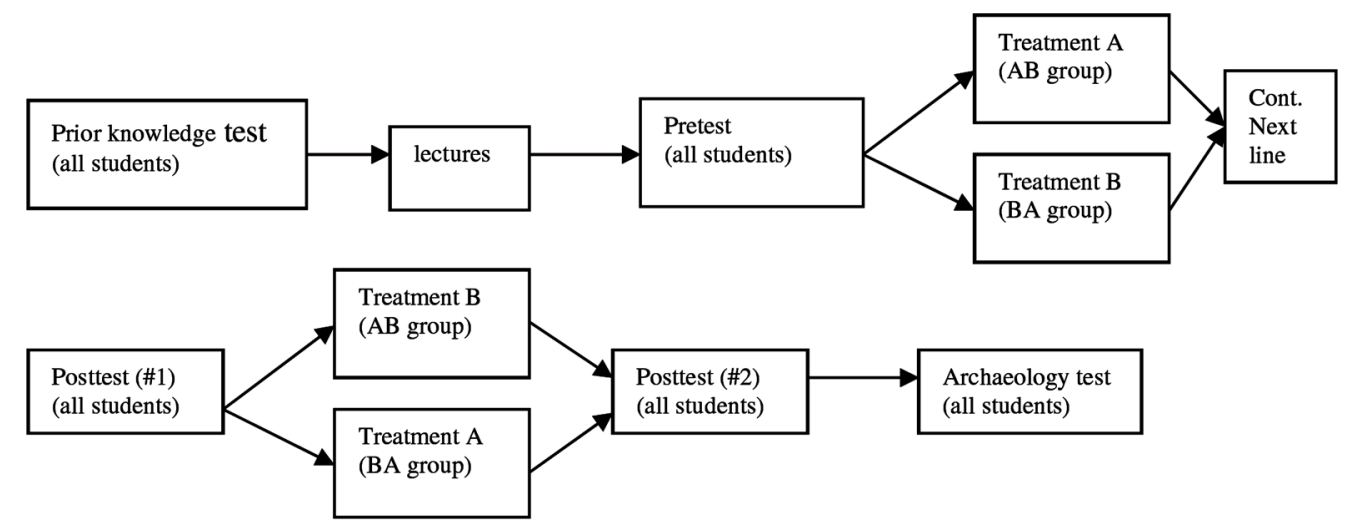

Figure 1. Experiment flow chart 
practice simulation. The palynology instructor provided the narration voice in all of the presentations. All presentations utilized the same surface story and deep structure format and were presented in accordance to the following Meichenbaum's cognitive modeling steps: 1. A full process example was presented prior to the practice segments. 2. The component part of the example was repeated at each of the four process steps. 3. After each component presentation, the student completed a practice component of that step (Figure 2).

All of the class periods were held in the same computer lab on the university campus. Headphones were provided for each student so computer narrations didn't present distracting background sound.

\section{Results}

The simulation data obtained from the first computer class period following the topic lectures were used as the pilot study. This set of data was analyzed to determine instrument reliability using a Cronbach's alpha score. Cronbach's alpha scores of $>0.70$ were deemed an acceptable level of reliability since alpha levels of 0.70 or
Figure 2. Entry page for simulations with treatment A or B. Image button loads a narrated modeled QuickTime $^{\mathrm{TM}}$ movie of the complete simulation process. "Click NOW!" button loads narrated modeled QuickTime movie of Segments $1-4$. Once the movie is finished the user can practice the step

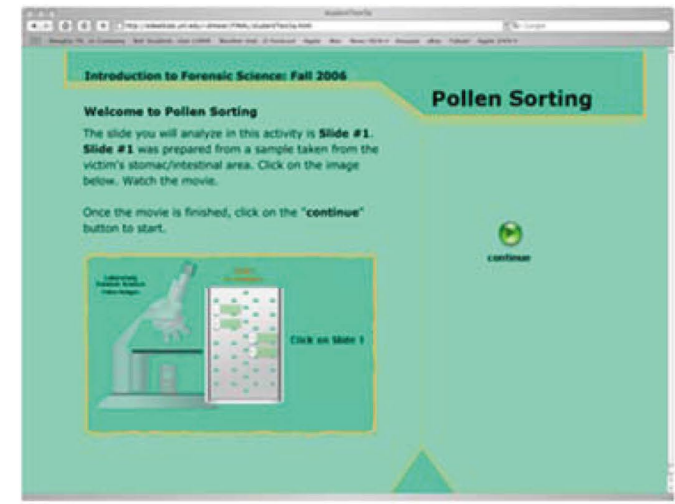

\section{Entry page}

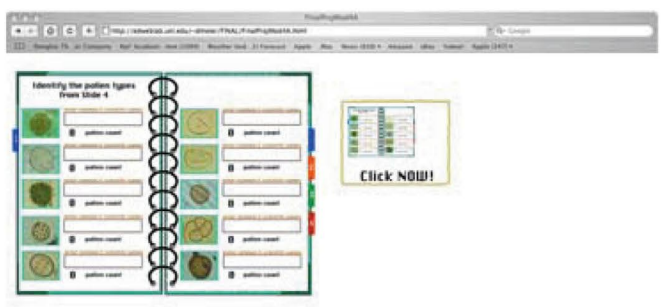

\section{Segment 2}

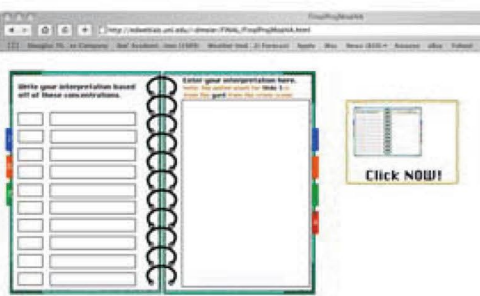

\section{Segment 1}
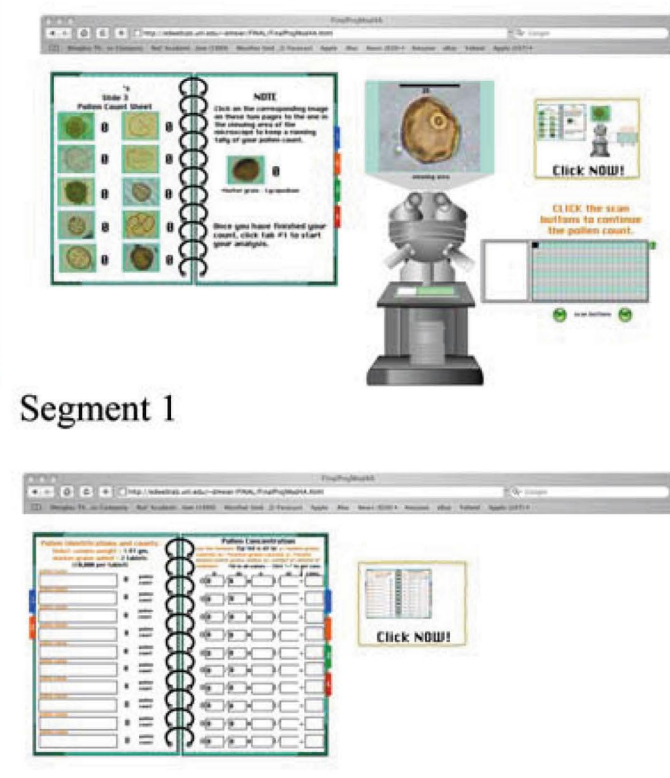

Segment 1
Segment 3 
higher are considered adequate as the cut-off criteria. A Cronbach's alpha was calculated for segment one- pollen count ( $\alpha=0.903)$; segment two - pollen ID ( $\alpha=0.741$, based on standardized items); segment three-pollen concentration ( $\alpha=0.967)$; segment four-interpretation ( $\alpha=0.769$, based on standardized items); and overall instrument ( $\alpha=0.894$, based on standardized items). Since all Cronbach's alpha scores were $>0.70$, the instrument was determined to be reliable for this study and no adjustments were made to improve the reliability. As previously stated, the instrument's validity was established by three expert forensic palynologists. The relevance of the knowledge obtained from the simulation was both field dependent and field independent since the technique was developed in another domain and then adapted into this domain of study.

\section{Prior Knowledge Test}

Prior knowledge of pollen counting, identification and site interpretation was measured for each student using the data gathered from a non-treatment computer practice simulation that the students worked through prior to the topic lectures. The AB group $(n=19)$ scored higher on the pollen counting and identification simulation $(M=29.34)$ than the BA group $(n=20)(M=28.18)$. This difference was not statistically significant, $t(37)=0.37, p>0.05$, two-tailed. Therefore, there was no significant difference found between the two treatment groups ( $\mathrm{AB}$ and $\mathrm{BA}$ ) on the basis of prior knowledge.

The average percentage score for the prior knowledge academic performance by the participants was 18.55 . In comparison, the average percentage score for the academic performance with lecture only (pretest) was 41.52 (Table 2).

\section{Mixed Model Analysis of Variance (ANOVA)}

To determine if embedded learning support in the form of elaborated and non-elaborated worked example modeling affected academic performance by undergraduate college students, a mixed model (one between and one within subjects design) ANOVA was used to analyze the data at $\alpha=0.05$.

Table 2. The means and percentages of accuracy (maximum score 155)

\begin{tabular}{lclrc}
\hline & $n$ & $M$ & \multicolumn{1}{c}{$S D$} & $\%$ \\
\hline Prior knowledge & 39 & 28.76 & 9.70 & 18.55 \\
Pretest (post lecture) & 39 & 64.36 & 25.21 & 41.52 \\
\hline
\end{tabular}

The mixed model ANOVA was conducted with the dependent variable being the simulation test score. This score evaluated the level of accuracy in counting, identification, concentration calculation, and interpretation of a simulated forensic pollen sample. The test scores were determined from a posttest that followed day 1 treatments, a posttest that followed day 2 treatments, and a pretest that was taken prior to treatments. The betweensubjects ANOVA was conducted with the independent variable being the group ID (AB or BA) (Table 3).

The sphericity assumption, for the within-subjects effect, was reviewed before the ANOVA results were examined to determine if it was tenable or not. To determine this, the Mauchly's Test of Sphericity was examined. The Mauchly's Test indicated a statistically nonsignificant difference, $W=0.92, p=0.22$. Preliminary analyses also indicated that the sphericity assumption is tenable, given a Huynh-Feldt value of 1.00.

\section{Within-subjects and Between-subjects Interaction}

With the sphericity assumption met, a univariate mixed method test was run. The univariate test indicated a statistically non-significant interaction between the within-subjects factor and the between-subjects factor, sphericity assumed, $F(2,74)=0.08, p=0.93$.

\section{Between-subjects Factor}

The results for the between-subjects factor main effect indicated a statistically significant group ID (AB, BA) effect, $F(1,37)=6.11, p<0.05$. This indicates that there is a higher academic performance in Group $\mathrm{AB}$ compared Group BA in all three tests (pretest, posttest \#1, posttest $\# 2$ ). The effect size for the analysis is large, $\eta_{p}^{2}=0.14$. In other words, $14 \%$ of the total variability of the level of accuracy can be explained by the group ID assignment, regardless of treatment presence.

\section{Within-subjects Factor}

The results for the within-subjects factor indicated a statistically significant worked example treatment effect, $F(2,74)=49.39, p<0.01$. The effect size for the analysis is large, $\eta_{p}^{2}=0.57$. In other words, $57 \%$ of the total vari-

Table 3. The means and standard deviations for level of accuracy (maximum score 155)

\begin{tabular}{llrl}
\hline Factor & & $M$ & \multicolumn{1}{c}{$S D$} \\
\hline Within-subjects & Pretest & 64.36 & 25.21 \\
& Posttest \#1 & 92.27 & 33.92 \\
& Posttest \#2 & 110.24 & 25.26 \\
Between-subjects & AB & 97.76 & 30.06 \\
& BA & 80.59 & 23.51 \\
\hline
\end{tabular}


Table 4. The mean difference and effect size for each pairwise comparison

\begin{tabular}{lll}
\hline Comparison & Mean difference & Cohen's $d$ \\
\hline Posttest \#1 vs. Pretest & $27.899^{\mathrm{a}}$ & 0.94 \\
Posttest \# 2 vs. Pretest & $45.918^{\mathrm{a}}$ & 1.82 \\
Posttest \#2 vs. Posttest \#1 & $18.020^{\mathrm{a}}$ & 0.61 \\
\hline
\end{tabular}

a Tukey's HSD statistically significant at $p<.05$

ability of the level of accuracy can be explained by repeated use of worked example modeling.

To determine where the significant differences were among the worked example treatment means, the pairwise Tukey's HSD Test was conducted on the mean differences. Table 4 shows that this analysis yielded three statistically significant pairwise differences. The first statistically significant pairwise difference was between Posttest \#1 group and Pretest group. The Posttest \#1 group yielded academic performance scores significantly higher than the Pretest group's scores. The second statistically significant pairwise difference was between Posttest \#2 group and Pretest group. The Posttest \#2 group yielded academic performance scores significantly higher than the Pretest group's scores. The third statistically significant pairwise difference was between Posttest \#2 group and Posttest \#1 group. The Posttest \#2 group yielded academic performance scores significantly higher than the Posttest \#1 group's scores.

For these results, a standardized mean difference measure was used for describing the pairwise differences between the groups even further by calculating the Cohen's $d$ effect size between each comparison. This measure expresses the mean difference between the groups in standard deviation units. As seen in Table 4 , the statistically significant comparison (Posttest \#1 group and Pretest group) yielded a value $(d=0.94)$ that Cohen (1988) would classify as a large effect size. These two group means are a little over $9 / 10$ of a standard deviation apart. The statistically significant comparison (Posttest \#2 group and Pretest group) yielded a value $(d=1.82)$ that Cohen (1988) would also classify as a large effect size. These two group means are "approaching" two standard deviations apart. The third statistically significant comparison (Posttest \#2 group and Posttest \#1 group) yielded a value $(d=0.61)$ that Cohen (1988) would classify as a medium-large effect size. These two group means are a little over $6 / 10$ of a standard deviation apart.

\section{Isomorph Test}

Academic performance in the archaeology simulation was measured for each student using the data gathered from a non-treatment archaeological pollen sample sim-
Table 5. The means and percentages of accuracy (maximum score 65)

\begin{tabular}{lllll}
\hline Transfer & $n$ & $M$ & $S D$ & $\%$ \\
\hline Forensic & 39 & 53.99 & 6.85 & 83.06 \\
Archaeology & 39 & 55.72 & 6.27 & 85.72 \\
\hline
\end{tabular}

ulation. To determine if embedded learning support affected academic performance in near transfer within an isomorphic context provided from a different domain, an independent $t$ test was used to analyze the data between the two treatment groups $(\mathrm{AB}, \mathrm{BA})$. The $\mathrm{AB}$ group $(n=19)$ scored higher on the pollen simulation $(M=57.66)$ than the BA group $(n=20)(M=53.78)$. This difference was not statistically significant, $t(37)=1.95$, $p>0.05$, two-tailed. Therefore, there was no significant difference detected between the two treatment groups $(\mathrm{AB}$ and $\mathrm{BA})$ on the basis of near transfer in an isomorphic context within a different domain.

The final forensic near transfer scores were re-calculated to reflect the performance with only the one overall pollen assemblage interpretation question that was answered in the archaeology test. An independent $t$ test was used to analyze the data between the $\mathrm{AB}$ and $\mathrm{BA}$ treatment groups. The $A B$ group again scored higher on the pollen simulation $(M=54.84)$ than the BA group $(M=53.13)$. This difference was, however, not statistically significant, $t(37)=0.78, p>0.05$, two-tailed. Therefore, there was no significant difference between the two treatment groups (AB and $\mathrm{BA})$ on the basis of near transfer performance that only included an overall interpretation of the pollen assemblage.

Comparison between the average percentage score for the forensic near transfer performance and for the archaeology near transfer performance, suggests a slightly better transfer success with the archaeology problem. As seen in Table 5, the average percentage score for the academic performance in participants' archaeology near transfer score was 85.72. In comparison, the average percentage score for the academic performance in participants' final forensic near transfer score was 83.06.

\section{Discussion}

The results of the prior knowledge simulation test indicate that both groups of students were similar in prior knowledge and can be classified as novice learners in the topic of forensic palynology analysis. Previous research has shown that novice learners have difficulties with selecting and organizing relevant material and of- 
ten form misconceptions (Rieber 1990b; Lowe 2003). The learner must be able to select relevant material, organize it into a meaningful representation so it will integrate into their existing knowledge (Mayer 2001). Rieber (1990a, 1990b) warns that novice learners often do not possess the ability to correctly interpret the learning activity. Some of the errors made in the prior knowledge and to a lesser extent in the pretest can be credited to a lack of knowledge with the activity as well as with the topic. Even though written instructions were included at each step in the simulation presented in the original class session, the students were noticeably unsure about how to proceed through the simulation activity. After obtaining information from the topic lectures and watching the instructor click through the sequence of steps in the activity, there still was a level of uncertainty on how to proceed through the process of the activity during the pretest. What the study results do allude to is that the worked example modeling successfully played the role of the expert coach, a strategy suggested by Rieber (1990a) to overcome this problem of indecisiveness with novice learners.

This research found a significant increase in academic performance with the inclusion of embedded learning support in the form of worked example modeling within a computer simulation. After exposure to one worked example, regardless of the presence of elaboration or not, these findings tentatively verify Ahn et al.'s (1992) conclusion that, when using an explanation-based leaning approach on concept formation, schema can be acquired from a single example in a knowledge-rich domain. Also supported was Renkl et al.'s (1998) conclusion that it is not necessary to include multiple examples for near transfer goals. However, results of this research do indicate a positive linear trend with exposure to multiple worked example modeling (Figure 3). The students' exposure to two worked example models may explain the similar performance success in the archaeology posttest (85.72\% accuracy) to the final forensic transfer posttest ( $83.06 \%$ accuracy).

The inclusion of embedded worked example models indicates a linear trend. One may suggest that this skill development is due to practice. To a certain extent, one would certainly assign a relationship of the positive increase in academic performance to the multiple attempts the students did of the "pretest/posttest" simulation. However, there was no immediate or delayed feedback given to the students on the numerous attempts. Thus, we return to the fact that previous research (Cooper and Sweller, 1987; Sweller and Cooper 1985) has found traditional practice-based problem solving strategies to be lacking in success. It would tentatively suggest that the practice success was only an effective method of acquiring cognitive skills for novices, once the embedded worked example modeling was present. The embedded

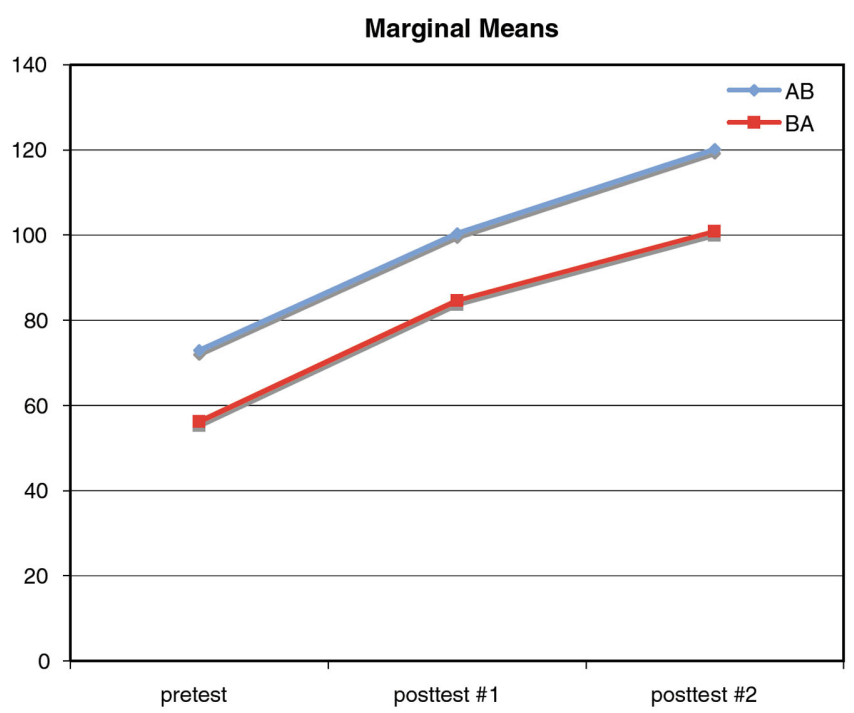

Figure 3. Profile plot of the mixed model ANOVA marginal means

worked example modeling elements, in this study, have shown significant research effects for better transfer $\left(\eta_{p}^{2}\right.$ $\left.=0.57, \eta_{p}^{2}=0.45, \eta_{p}^{2}=0.36\right)$ suggesting reduction of cognitive load for the novice students. This is not surprising in that the instructional design of this research's simulation activity incorporates the nine ways of reducing cognitive overload in multimedia learning (Mayer and Moreno 2003).

When considering the effectiveness of the embedded worked example modeling in each step, some research studies (Clarke et al. 2005; Kester et al. 2004a, 2004b; Pollock et al. 2002) argue that a part-whole approach is effective in reducing intrinsic load in learning complex tasks. However, this study utilizing Meichenbaum's steps for cognitive modeling has shown that providing a complete presentation of the complexity of the process at the beginning followed with short segment clips at each step of the process, has a significant effect on performance. These results connect this present research's significance of the worked example modeling to the notion that a whole-part approach is a successful method through which to reduce intrinsic load in complex learning tasks. Previous literature (Dufresne et al. 1992; van Merriënboer et al. 2006) has suggested that one way to present a whole-part approach is "... to constrain learners' performance, either through forcing them to behave as an expert would do by requiring them to successfully complete a particular problem-solving phase before entering a next phase or through the use of particular tasks formats such as worked examples and completion tasks" (van Merriënboer et al. 2006, p. 348). The Meichenbaum steps utilize this enforcement of expert behavior in requiring the completion of each task before entering the next task or phase. This whole-part approach was ef- 
fective in academic performance of novice learners and suggests that presentation of the complete process with individual follow up segments at each step of the process does reduce intrinsic load for these learners as suggested by Meichenbaum (1977).

This study also suggests that the delayed use of feedback was a factor contributing to the success of transfer. This delayed use of feedback is supported by van Merriënboer, et al. (2006) as a method to induce germane cognitive load. A study by Robins and Mayer (1993) also “... found superior transfer test performance for learners who received sets of worked examples together with infrequent feedback" (van Merriënboer et al. 2006, p. 349).

The results from the current study's repeated measure performance effect size $\left(\eta_{p}^{2}=0.57\right)$ provides additional support for Lee's (1999) findings that the effectiveness of using computer simulation practice in science education has an average effect size of 0.54 .

It was hypothesized that procedural practice simulations with embedded elaborated worked example modeling compared to non-elaborated worked example modeling would provide a greater significant cognitive transfer with novice learners due to reduction in cognitive load. However, no significant difference was found in utilizing elaborated vs. non-elaborated worked example modeling. This study's practice simulation was formulated to represent a process developed in a wellstructured scientific domain. Thus, this finding is attributed to the fact that the goal state is well defined and that there is only one path that will lead to the correct (acceptable) solution. This then does not support the rationale by van Gog et al. (2004) for utilizing the "expert" why and how in worked examples. However, their suggestion that the addition of the "expert" why would foster better understanding in less structured domains has not been discounted and further research is suggested. van Merriënboer et al. (2006), when discussing methods to induce germane cognitive load, refers to a study by Renkl (2002) that "...indicated using guidance, in the form of a minimalist description of the probabilistic rule that was used in the worked example provided, had beneficial effects on learning" (van Merriënboer et al. 2006, pp. 348-349). Thus, the inclusion of non-elaborated worked example modeling may actually be more beneficial in this regard.

The present research has demonstrated a significant linear trend of exposure to multiple worked example modeling. After exposure to two worked example models, the students performed as well on the archaeology transfer posttest (85.72\%) as the final forensic near transfer posttest $(83.06 \%)$. Renkl et al. (1998) concluded that it is necessary to include multiple examples when far transfer is the goal, but this may be also necessary in transfer between isomorphs.

In reviewing this study, the concept of analyzing pollen samples from a human occupation site to deter- mine human activity within the context of two different domains can be argued that the transfer of knowledge is the same and only represents near transfer in both. However, Perkins (1992) presents a discussion of transfer with isomorphs that pertains to this argument. He states, "[I]t is not clear whether one should consider study of problem isomorphs near or far transfer, because isomorphs are near identical structurally but very different in external trappings. In any case, subjects usually do not recognize the connection between one isomorph and the other and hence do not carry over strategies they have acquired while working with one to the other. However, if the relationship is pointed out, then subjects can do so fruitfully (Simon and Hayes 1977)" (Perkins 1992, p. 4). So, if one views the use of palynology techniques in forensic science and archaeology as isomorphs, with the same logical structure in different physical terms (the forensic structure presented entirely with the present day time frame and a murder investigation context while the archaeology structure is presented with a prehistoric time frame in a hunter-gatherer habitation context), the success lies in the order of practice with the archaeology simulation following the forensic simulation. This allowed the students to successfully carry over the process strategies. The argument for domain transfer success is a necessary argument when validation of scientific techniques, developed for analysis in one domain, is to be accepted as a valid technique in other domains. In the current study, pollen analysis was taught as an analytical tool in a science field that has incorporated multiple hard science techniques to support conclusions in a court of law (James and Nordby 2005). Bryant et al. (1990, p. 193) define forensic palynology as "... the science of applying modern and fossil pollen and spores (palynomorphs) to help solve legal problems." The utilization of forensic palynology in solving legal problems was first documented in 1959 (Bryant and Mildenhall 1998). References to the use of palynology in archaeology, however, can be traced back to the 1920s (Kapp et al. 2000). Archaeological palynology has been utilized in the natural science field of archaeology as a method of interpreting the health, diet, and activity patterns of ancient populations.

"Instructional methods that explicitly aim at transfer of learning must carefully balance both complementary dimensions, and facilitate the interpretive aspects of knowing for those aspects of a complex task that are different from problem to problem situation as well as facilitate the applicative aspects of knowing for those aspects of a complex task that are highly similar from situation to situation (van Merriënboer 1997)" (van Merriënboer et al. 2006, p. 346). The results from the current study suggest that, with the adaptation of practice simulation utilizing the same mechanical procedure in two different physical domain contexts, but containing similar interpretation logic, the practice simulation incor- 
porates an instructional method that contains aspects of transfer of knowledge in science as well as other natural science domains through the utilization of the worked example modeling.

\section{Conclusions}

This research study focused on embedded worked example modeling within practice simulations as an instructional design model for enhancing knowledge transfer for promotion of schema acquisition. The findings suggest that embedded worked example modeling within practice simulations can be an effective method for transfer of learning with novice learners. In addition, the findings suggest that this is a method that can be utilized as part of course curriculum for enhanced instruction on complex tasks.

\section{References}

Ahn W, Brewer WF, Mooney RJ (1992) Schema acquisition from a single example. J Exp Psychol Learn Mem Cogn 18(2):391-412

Atkinson RK, Derry SJ, Renkl A, Wortham D (2000) Learning from examples: Instructional Principles from the worked examples research. Rev Educ Res 70(2):181-214

Baddeley A (1986) Working memory. Clarendon Press, Oxford

Bourne LE, Goldstein S, Link WE (1964) Concept learning as a function of availability of previously learned information. J Exp Psychol 67:439-448

Bransford JD, Brown AL, Cocking RR (eds.) (2000) How people learn: Brain, mind, experience, and school. National Academy Press, Washington, DC

Bruner JS, Goodnow J, Austin G (1956) A study of thinking. Wiley, New York

Bruning RH, Schraw GJ, Norby MM, Ronning RR (2004) Cognitive psychology and instruction, 4 th edn. Pearson Education, Inc., New Jersey

Bryant VM, Jones JG, Mildenhall DC (1990) Forensic palynology in the United States of America. Palynology 14:193-208

Bryant VM, Mildenhall DC (1998) Forensic palynology: A new way to catch crooks. In Bryant V, Wrenn J (eds.) New developments in palynomorph sampling, extraction, and analysis. AASP Contribution Series \#33. American Association of Stratigraphic Palynologists, Dallas, pp 145-155

Carroll WM (1994) Using worked examples as an instructional support in the algebra classroom. J Educ Psychol 86:360-367

Catrambone R (1994a) The effects of labels in example on problem solving transfer. In Ram A, Eiselt K (eds.) Proceedings of the sixteenth annual conference of the cognitive science society. Erlbaum, Hillsdale, NJ, pp 159-164

Catrambone R (1994b) Improving examples to improve transfer to novel problems. Mem Cognit 22:606-615
Catrambone R (1995) Aiding subgoal learning: Effects on transfer. J Educ Psychol 87:5-17

Catrambone R (1996) Generalizing solution procedures learned from examples. J Exp Psychol Learn Mem Cogn 22:1020-1031

Chandler TN, Chaillé C (1993) Process highlighters in a computer simulation: Facilitation of theory-oriented problem solving. J Educ Comput Res 9(2):237-263

Clarke T, Ayres P, Sweller J (2005) The impact of sequencing and prior knowledge on learning mathematics through spreadsheet applications. Educ Technol Res Dev 53:15-24

Cohen J (1988) Statistical power analysis for the behavioral sciences, 2nd edn. Lawrence Erlbaum Associates, Hillsdale, NJ

Cooper G, Sweller J (1987) Effects of schema acquisition and rule automation on mathematical problem-solving transfer. J Educ Psychol 79:347-362

Dufresne RJ, Gerace WJ, Thibodeau-Hardiman P, Mestre JP (1992) Constraining novices to perform expert-like problem analyses: Effects on schema acquisition. J Learn Sci 2:307-331

Gick ML, Holyoak KJ (1983) Schema induction and analogical transfer. Cogn Psychol 15:1-38

James SH, Nordby JJ (2005) Forensic science: An introduction to scientific and investigative techniques, 2nd edn. CRC Press, Boca Raton, FL

Jeung H, Chandler P, Sweller J (1997) The role of visual indicators in dual sensory mode instruction. Educ Psychol 17:329-433

Kapp RO, Davis OK, King JE (2000) Pollen and spores, 2nd edn. The American Association of Stratigraphic Palynologists Foundation, College Station, TX

Kester L, Kirschner PA, van Merriënboer JJG (2004a) Just in time presentation of different types of information in learning statistics. Instruct Sci 32:233-252

Kester L, Kirschner PA, van Merriënboer JJG (2004b) Information presentation and troubleshooting in electrical circuits. Int J Sci Educ 26:239-256

Larkin JH (1977) Skilled problem solving in experts (Tech Rep). University of California, Group in Science and Mathematics Education, Berkeley

Lee J (1999) Effectiveness of computer-based instructional simulation: A meta-analysis. Int J Instruct 26(1):71-85

Lowe RK (2003) Animation and learning: Selective processing of information in dynamic graphs. Learn Instruct 13(2):157-176

Mayer RE (2001) Multimedia learning. Cambridge University Press, Cambridge, UK

Mayer RE, Moreno R (2003) Nine ways to reduce cognitive load in multimedia learning. In Bruning R, Horn CA, Pytlik-Zillig LM (eds.) Web-based learning: What do we know? where do we go? Information Age Publishing, Connecticut, pp 23-44

Meichenbaum D (1977) Cognitive behavior modification: an integrative approach. Plenum, New York

Paas F, van Merriënboer J (1994) Variability of worked examples and transfer of geometrical problem-solving skills: A cognitive-load approach. J Educ Psychol 86:122-133 
Perkins DN (1992) Transfer of learning. Contribution to the International Encyclopedia of Education, 2nd edn. Pergamon Press, Oxford, England. http://0-learnweb.harvard.edu. library.unl.edu/alps/thinking/docs/traencyn.htm. Accessed 21 Jan 2006

Pollock E, Chandler P, Sweller J (2002) Assimilating complex information. Learn Instruct 12:61-86

Quilici JL, Mayer RE (1996) Role of examples in how students learn to categorize statistics word problems. J Educ Psychol 88:144-161

Reed SK (1993) A schema-based theory of transfer. In Detterman DK, Sternberg RJ (eds.) Transfer on trial: Intelligence, cognition, and instruction. Ablex, Norwood, New Jersey, pp 39-67

Reed SK, Bolstad CA (1991) Use of examples and procedures in problem solving. J Exp Psychol Learn Mem Cogn 17:753-766

Renkl A (1997) Learning from worked-out examples: A study on individual differences. Cogn Sci 21:1-29

Renkl A (2002) Worked-out examples: Instructional explanations support learning by self-explanations. Learn Instruct 12:529-556

Renkl A, Stark R, Gruber H, Mandl H (1998) Learning from worked-out examples: The effects of example variability and elicited self-explanations. Contemp Educ Psychol 23:90-108

Rieber LP (1990a) Animation in computer-based instruction. Educ Technol Res Dev 38(1):77-86

Rieber LP (1990b) The effects of computer animation on adult learning and retrieval tasks. J Comp-Based Instruct 17(2):46-52

Robins S, Mayer RE (1993) Schema training in analogical reasoning. J Educ Psychol 85:529-538

Simon HA, Hayes JR (1977) Psychological differences among problem isomorphs. In Castelan NJ, Pisoni DB, Potts GR (eds.) Cognitive theory, vol. 2. Erlbaum, Hillsdale, NJ

Simon DP, Simon HA (1978) Individual differences in solving physics problems. In Siegler RR (ed) Children's thinking: What develops?. Erlbaum, Mahwah, NJ, pp 40-74

Spiro RJ, Feltovich PJ, Coulson RL, Anderson DK (1989) Multiple analogies for complex concepts: Antidores for anal- ogy-induced misconceptions in advanced knowledge acquisition. In Vosniadou S, Ortony A (eds.) Similarity and analogical reasoning. Cambridge University Press, New York, pp. 498-531

Stark R, Graf M, Renkl A, Gruber H, Mandl H (1995) Förderung von Hanlungskompetenz durch geleitete Problemlösen und multiple Lernkontexte [Fostering action competence by guided problem solving and multiple learning contexts]. Zeitschrift für Entwicklungspsychologie und Pädagogische Psychologie 27:289-312

Sweller J.(1999) Instructional design in technical areas. ACER Press, Victoria, Australia

Sweller J, Cooper GA (1985) The use of worked examples as a substitute for problem solving in learning algebra. Cogn Instruct 2:59-89

Tennyson RD, Wooley FR, Merrill MD (1972) Exemplar and nonexemplar variables which produce correct concept classification behavior and specified classification errors. J Educ Psychol 63:144-152

Trafton JG, Reiser BJ (1993) The contributions of studying examples and solving problems to skill acquisition. In Polson $\mathrm{M}$ (ed.) Proceedings of the fifteenth annual conference of the cognitive science society. Erlbaum, Hillsdale, NJ, pp 1017-1022

van Gog T, Paas F, van Merriënboer JJG (2004) Process-oriented worked examples: Improving transfer performance through enhanced understanding. Instruct Sci 32:83-98

van Merriënboer JJG (1997) Training complex cognitive skills: A four-component instructional design model for technical training. Educational Technology Publications, Englewood Cliffs, NJ

van Merriënboer JJG, Kester L, Paas F (2006) Teaching complex rather than simple tasks: Balancing intrinsic and germane load to enhance transfer of learning. Appl Cogn Psychol 20:343-352

Ward M, Sweller J (1990) Structuring effective worked examples. Cogn Instruct 7:1-39

Zhu X, Simon HA (1987) Learning mathematics from examples and by doing. Cogn Instruct 4:137-166 